\title{
The Use of Gel-stabilized Model Systems for the Study of Microbial Processes in Polluted Sediments
}

\author{
By PHILIP MORGAN* AND ROBERT J. WATKINSON \\ Shell Research Ltd, Sittingbourne Research Centre, Sittingbourne, Kent ME9 8AG, UK
}

(Received 10 August 1988; revised 23 October 1988; accepted 23 November 1988)

\begin{abstract}
Gel-stabilized model sediment ecosystems were prepared using agar and colloidal silica as gelling agents and were employed in studies of the effects and degradation of xenobiotics in marine and freshwater sediments. All models produced physicochemical and microbiological profiles characteristic of sediments. The fate of 3-nitrophenol was studied in a freshwater system and the compound was found to be readily distributed through the gel column and to be rapidly degraded. The release of the nitro-group during metabolism resulted in the accumulation of nitrate in the aerobic portion of the gel column. The fate of a $1: 1$ hexadecane/naphthalene mixture was investigated using a seawater model system. The metabolism of these compounds resulted in oxygen depletion in the gel column and in a decrease in the population size of aerobic heterotrophic bacteria. Conversely, the populations of anaerobic heterotrophic bacteria and sulphate-reducing bacteria were significantly increased. The data are discussed with particular respect to the practical uses of gel-stabilized model ecosystems in research into the microbiology of sediments.
\end{abstract}

\section{INTRODUCTION}

The study of microbiological processes in sediments is complicated by the numerous spatial gradients present and the physical structure of the environment itself. Consequently, investigations into the microbial ecology of sediments are frequently limited by available experimental techniques to overall measurements of physiological processes in intact sediment cores or to the use of destructive methodologies. Whilst many valuable data have been obtained by such means, there is relatively little information available concerning the effects of environmental contaminants on sediment micro-organisms. Wimpenny et al. (1981) described the use of agar gel-stabilized columns as models of vertically stratified ecosystems. They found that a sloppy agar permitted almost unrestricted solute diffusion and microbial migration but stabilized the system against convection currents and mechanical disturbance. The technique was refined by MacFarlane et al. (1984) and was employed to study microbial activities in an estuarine sediment, particularly those involved in nitrogen cycling, sulphate reduction and methanogenesis. These workers observed that the technique provided a realistic and accurate model of the natural environment and enabled analyses to be performed that would have been difficult to perform by other means.

The aim of this study was to develop and investigate the use of gel-stabilized model ecosystems as a method for the investigation of microbial populations and metabolic processes in sediments in the presence and absence of defined concentrations of xenobiotic compounds. The use of both freshwater and marine sediments was investigated in order to confirm that gelstabilized systems can be applied to both sediment types.

Abbreviations: SRB, sulphate-reducing bacteria; MPN, most probable number. 


\section{METHODS}

Sediment samples. Freshwater sediment was obtained from a pond at Rodmersham, Kent. The sediment was of clay-like consistency and a large amount of decaying vegetative material was present. Marine sediment was obtained from a harbour at Conyer, Kent, which was visibly contaminated with oil. The hydrocarbon material was probably diesel or light fuel oil from nearby vessels and storage tanks. Samples were collected by filling sterile glass jars to the brim with sediment, tightly capping them and returning them to the laboratory for immediate use.

Preparation of agar-stabilized model sediment systems. Agar-stabilized systems were employed for studies with freshwater sediment. The model ecosystems were prepared in sterile 1 litre glass breakers. The basal gel layer

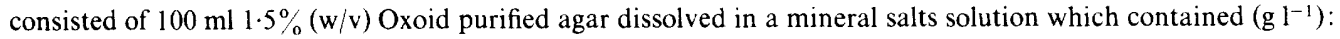
$\mathrm{MgSO}_{4} .7 \mathrm{H}_{2} \mathrm{O}, 0 \cdot 15 ; \mathrm{CaCl}_{2} .6 \mathrm{H}_{2} \mathrm{O}, 0.01 ; \mathrm{NaHCO}_{3}, 0.5 ; \mathrm{KH}_{2} \mathrm{PO}_{4}, 0.4 ; \mathrm{K}_{2} \mathrm{HPO}_{4}, 4 \cdot 2 ; \mathrm{FeSO}_{4} .7 \mathrm{H}_{2} \mathrm{O}, 0.005 ;$ cycloheximide (Sigma), 0.05. Once this basal agar layer had solidified, the sediment collected was mixed $1: 1$ with nitrogen-sparged mineral salts solution and $100 \mathrm{ml}$ of the slurry was added to the surface of the agar layer under a blanket of nitrogen gas. The slurry was immediately covered with $550 \mathrm{ml}$ sterile $0.3 \%$ agar prepared in mineral salts solution and cooled to $45^{\circ} \mathrm{C}$. No mixing of the slurry and gel layers was observed. Once this gel layer had set, a further $50 \mathrm{ml} 0.3 \%$ agar solution was applied to the surface; this solution was supplemented with $12 \mathrm{mg} 3-$ nitrophenol $(\mathrm{BDH})$ for the production of contaminated systems. In addition to inoculated gels, sterile control gels were prepared as described above except that the sediment slurry was omitted and replaced with a further $100 \mathrm{ml}$ $1.5 \%$ agar solution.

Preparation of silica gel-stabilized model sediment systems. A $100 \mathrm{ml}$ basal agar layer was prepared as described above except that artificial seawater containing $0.05 \mathrm{~g}$ cycloheximide $\mathrm{l}^{-1}$ and $10 \mathrm{~mm}-\left(\mathrm{NH}_{4}\right)_{2} \mathrm{SO}_{4}$ was employed. The artificial seawater contained $\left(\mathrm{g} \mathrm{l}^{-1}\right): \mathrm{NaCl}, 24 \cdot 530, \mathrm{Na}_{2} \mathrm{SO}_{4}, 4 \cdot 090, \mathrm{MgCl}_{2} .6 \mathrm{H}_{2} \mathrm{O}, 11 \cdot 110, \mathrm{CaCl}_{2} .2 \mathrm{H}_{2} \mathrm{O}$, $1.535 ; \mathrm{KCl}, 0.695 ; \mathrm{NaHCO}_{3}, 0.201 ; \mathrm{KBr}, 0.100 ; \mathrm{H}_{3} \mathrm{BO}_{3}, 0.027 ; \mathrm{SrCl}_{2} .2 \mathrm{H}_{2} \mathrm{O}, 0.042 ; \mathrm{NaF}, 0.03$. This basal layer was overlaid as described above with $100 \mathrm{ml}$ of a $1: 1$ sediment/artificial seawater slurry. This was immediately covered with $550 \mathrm{ml} \mathrm{5.5 \%}(\mathrm{w} / \mathrm{v})$ colloidal silica gel $(\mathrm{BDH})$ dispersed in artificial seawater. Once this gel was set, a further $50 \mathrm{ml}$ silica gel was applied, supplemented in the contaminated systems with $12 \mathrm{mg}$ hexadecane (Sigma) and $12 \mathrm{mg}$ naphthalene (BDH).

Incubation of gels. All systems were wrapped in aluminium foil to exclude light and an aluminium foil lid was tightly taped over the beaker aperture in order to minimize evaporative loss. Gels were incubated with the minimum of disturbance at $20^{\circ} \mathrm{C}$.

Sampling of gels. Cores were removed at intervals from gels by means of a sterile cork borer of $11 \mathrm{~mm}$ internal diameter. The gel columns were extruded, sectioned aseptically into $10 \mathrm{~mm}$ lengths and analysed immediately.

Determination of carbon substrate profile. For 3-nitrophenol analysis, core sections were homogenized with $1.5 \mathrm{ml}$ sterile distilled water and $0.5 \mathrm{ml}$ conc. $\mathrm{HCl}$ was added. The samples were extracted with two $10 \mathrm{ml}$ portions of ethyl acetate. These were pooled, dried over anhydrous $\mathrm{Na}_{2} \mathrm{SO}_{4}$ and solvent removed under a stream of nitrogen gas. The residue was dissolved in $1 \mathrm{ml}$ sterile distilled water and insoluble material was removed by centrifugation in an Eppendorf $5414 \mathrm{~S}$ microfuge for $10 \mathrm{~min}$. To the supernatant was added two drops of $20 \%(\mathrm{w} / \mathrm{v}) \mathrm{NaOH}$ and the absorbance at $390 \mathrm{~nm}$ (Raymond \& Alexander, 1971) was determined using a Cecil CE393 spectrophotometer. The concentration of 3-nitrophenol was determined by reference to a standard curve of this compound.

Hydrocarbons were extracted from homogenates of silica gel samples by vigorous shaking with two $5 \mathrm{mi}$ portions of dichloromethane. Analysis was performed by gas chromatography on a $25 \mathrm{~m}$ Chrompack CP-SIL-5$\mathrm{CB}$ capillary column in an Erba 4610 high-resolution gas chromatograph. Helium was employed as the carrier gas and detection was by means of a flame ionization detector. The chromatograph was operated at a temperature gradient from 55 to $300^{\circ} \mathrm{C}$ ramped at $5^{\circ} \mathrm{C} \mathrm{min}$ min a $^{-1}$ plus min hold at $300^{\circ} \mathrm{C}$.

Determination of inorganic ions. Sections of gel core were homogenized in $10 \mathrm{ml}$ sterile distilled water and particulate matter was removed by centrifugation as described above. Analysis was performed on a Dionex highperformance ion chromatography system fitted with an $\mathrm{AS} 3$ anion-exchange column for $\mathrm{NO}_{2}^{-}, \mathrm{NO}_{3}^{-}$and $\mathrm{SO}_{4}^{2-}$ determinations and with a CSl cation-exchange column for the determination of $\mathrm{NH}_{4}^{+}$.

Determination of bacterial numbers. Sulphate-reducing bacteria (SRB) were determined by the most probable number (MPN) method using medium B of Postgate (1979) prepared in distilled water or artificial seawater, as appropriate. Duplicate $10 \mathrm{~mm}$ core sections were homogenized in $9 \mathrm{ml}$ medium and each was serially diluted in duplicate. Bottles were incubated at $20^{\circ} \mathrm{C}$ for $14 \mathrm{~d}$ and blackening of the medium together with visible turbidity was taken as evidence for growth. MPN was determined by means of a microcomputer program modified from that of Clarke \& Owens (1983).

All other bacterial numbers were determined using duplicate gel core slices homogenized in $9 \mathrm{ml}$ portions of quarter-strength Ringer's solution or artificial seawater, as appropriate, and serially diluted.

Denitrifying bacteria were determined using an MPN method (MacFarlane \& Herbert, 1984). Four replicate $1 \mathrm{ml}$ portions of each dilution were inoculated into $9 \mathrm{ml}$ portions of nutrient broth (Oxoid) $+10 \mathrm{mM}^{-\mathrm{KNO}_{3}}$ dispensed into test tubes and containing Durham tubes. Gas accumulation in the Durham tube following $7 \mathrm{~d}$ static incubation at $20^{\circ} \mathrm{C}$ was deemed a positive result. 
Bacteria dissimilating nitrate to ammonia were determined by a micro-MPN method employing the medium of Jones et al. (1982). Portions $(180 \mu 1)$ of medium were aseptically dispensed into the wells of sterile microtitre plates and four replicate $20 \mu \mathrm{l}$ samples of the desired inoculum dilutions were added. Plates were incubated for $14 \mathrm{~d}$ at $20{ }^{\circ} \mathrm{C}$ in an anaerobic jar under an atmosphere of $\mathrm{H}_{2} / \mathrm{CO}_{2}$ generated by means of the Oxoid Gaspak system. At the end of the incubation period one drop of $20 \%(\mathrm{w} / \mathrm{v}) \mathrm{NaOH}$ was added to each well and the presence of $\mathrm{NH}_{4}^{+}$ determined by means of Machery-Nagel ammonium test paper strips (Camlab).

Ammonia-oxidizing bacteria were determined by a micro-MPN method employing the medium of Alexander \& Clark (1965). Microtitre plates were incubated aerobically in a moist atmosphere for $14 \mathrm{~d}$ at $20^{\circ} \mathrm{C}$. Positives were detected by means of the presence of $\mathrm{NO}_{2}^{-}$or $\mathrm{NO}_{3}^{-}$in the medium as ascertained by Machery-Nagel ' $\mathrm{Nitratesmo}$ ' test paper strips (Camlab).

Nitrite-oxidizing bacteria were determined by the micro-MPN method using the medium of Aleem \& Alexander (1958). Microtitre plates were inoculated as described above and incubated aerobically in a moist atmosphere for $14 \mathrm{~d}$ at $20^{\circ} \mathrm{C}$. Growth of nitrite-oxidizers was demonstrated by the presence of $\mathrm{NO}_{3}^{-}$as ascertained by means of 'Nitratesmo' test papers.

Total heterotrophic bacteria in marine systems were determined by total viable counts on nutrient agar prepared in artificial seawater. Plates were incubated at $20^{\circ} \mathrm{C}$ for $14 \mathrm{~d}$ either aerobically or in an Oxoid Gaspak system anaerobic jar. Numbers of hexadecane-utilizing bacteria were determined by the total viable count method using agar-solidified artificial seawater in which solid test compound $\left(20 \mathrm{mg} \mathrm{l}^{-1}\right)$ had been dispersed. Plates were incubated at $20^{\circ} \mathrm{C}$ for $14 \mathrm{~d}$.

\section{RESULTS}

\section{Gel structure}

The agar-solidified gels were transparent and easy to sample. The same gels were employed for sampling over the incubation period, and the voids created by core removal were observed to be rapidly filled by horizontal flow. Blackened bands resulting from the production of $\mathrm{H}_{2} \mathrm{~S}$ by SRB developed during the incubation period. These were more intense in the nitrophenolsupplemented gels and were present below a depth of approximately $10 \mathrm{~mm}$ in the supplemented gels and $30 \mathrm{~mm}$ in the unsupplemented gels. The silica-gel-stabilized systems were more difficult to study since they were virtually opaque and, in order to obtain a gel that could be cored and sectioned, were necessarily more rigid than those prepared using agar. The silica gel model systems supplemented with hexadecane and naphthalene had very profuse microbial growth on the gel surface during the latter half of the incubation period. No banding effects due to $\mathrm{H}_{2} \mathrm{~S}$ production were seen but there was a general blackening of the gel column during the incubation period. The silica gels were particularly prone to shrinkage owing to water loss during the incubation period. Over 12 weeks the length of the upper gel column was reduced by approximately $20 \%$ whereas in the agar-solidified systems the column length was reduced by less than $5 \%$.

\section{Xenobiotic profiles}

3-Nitrophenol diffused rapidly through the sloppy agar gel column and an equilibrium concentration of approximately $20 \mu \mathrm{g} \mathrm{ml}^{-1}$ was attained throughout the gel in the absence of microbial activity. In inoculated gels similar diffusion was noted but the compound was virtually undetectable at the end of the 12 week incubation period. It proved impossible to detect naphthalene in any of the completed gel systems but hexadecane was present and was observed to be distributed through the gel column of uninoculated model systems. A decrease in concentration during the 12 week incubation period of inoculated gels was observed.

\section{Physiochemical gradients}

Steep oxygen gradients developed in inoculated gels and, using a commercial oxygen electrode (tip diameter $8 \mathrm{~mm}$ ), no oxygen was detectable in any gel below a gel depth of $25 \mathrm{~mm}$ (Fig. $1 \mathrm{a}$ ). There were differences between the $\mathrm{pH}$ profiles of unsupplemented and supplemented gel systems (Fig. 1b). 3-Nitrophenol supplementation resulted in more alkaline conditions, whereas hydrocarbon supplementation resulted in a $\mathrm{pH}$ profile more acidic than the unsupplemented controls. The profiles of metabolically significant ions were investigated in the agar-stabilized 

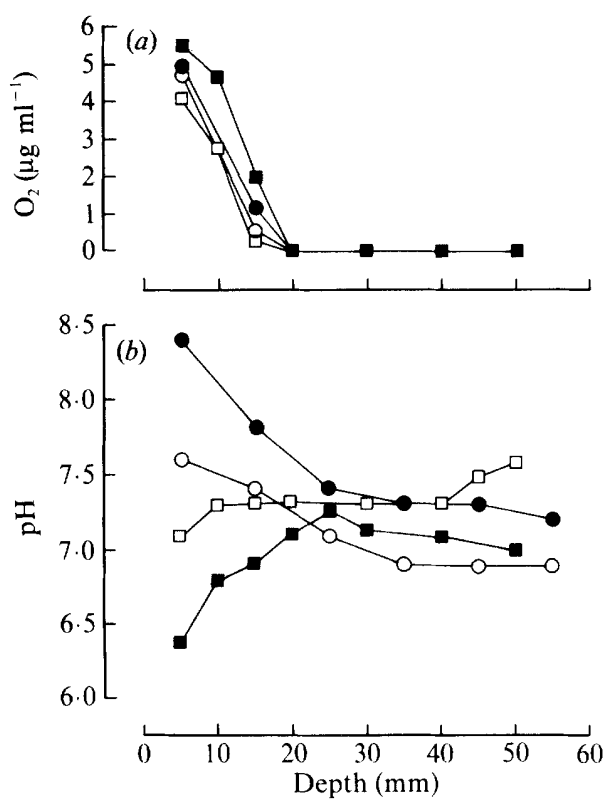

Fig. 1

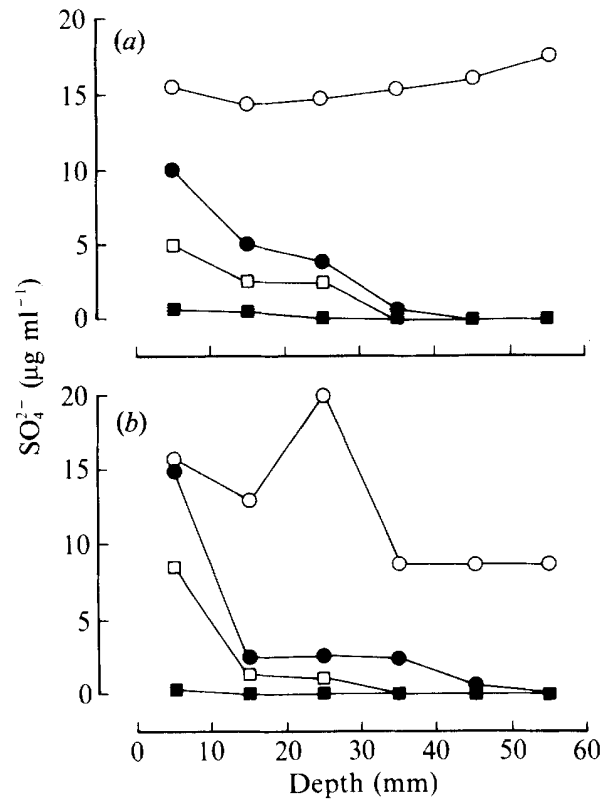

Fig. 2

Fig. 1. (a) Oxygen and (b) $\mathrm{pH}$ profiles in gel-stabilized model sediment ecosystems after 12 weeks incubation. $\bigcirc$, Freshwater sediment, unsupplemented; $\bigcirc$, freshwater sediment + 3-nitrophenol; $\square$, marine sediment, unsupplemented; $\square$, marine sediment + hexadecane/naphthalene $(1: 1)$.

Fig. 2. Development of sulphate profiles in gel-stabilized model freshwater sediment systems. $(a)$ Unsupplemented; (b) 3-nitrophenol supplemented. $\bigcirc, 2$ weeks;, 4 weeks; $\square, 6$ weeks; $\square, 8$ weeks.

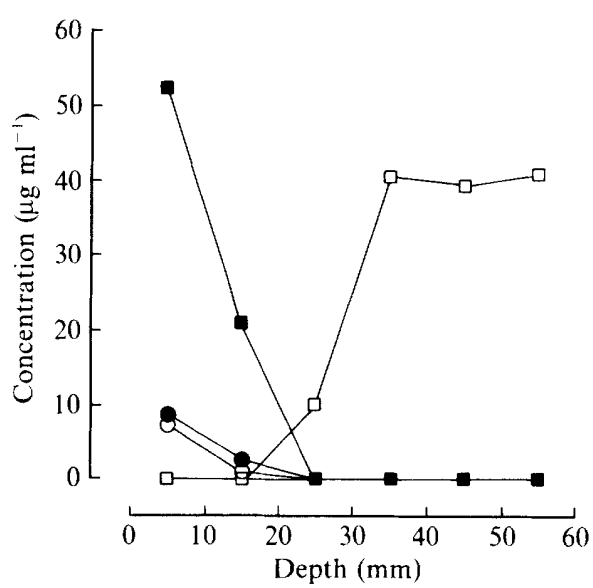

Fig. 3

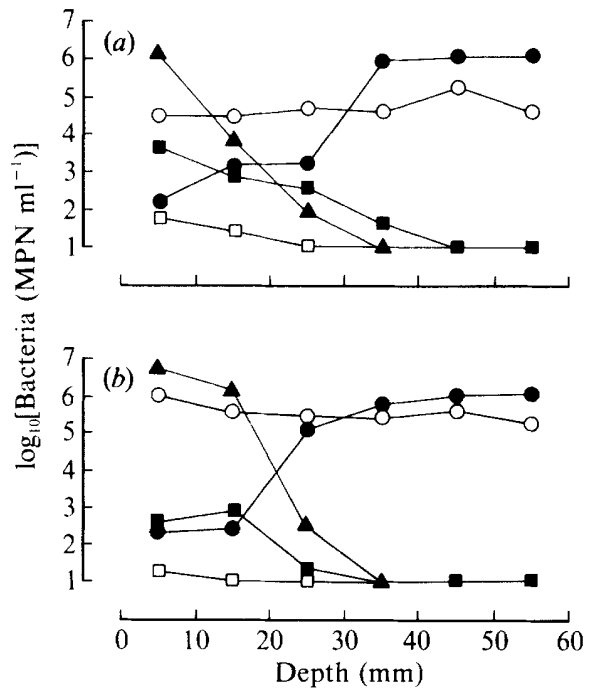

Fig. 4

Fig. 3. Profiles of nitrogenous ions in gel-stabilized freshwater sediment model ecosystems after 12 weeks incubation. $\mathrm{O}, \mathrm{NH}_{4}^{+}, 3$-nitrophenol-supplemented gel; $\mathrm{O}, \mathrm{NH}_{4}^{+}$, unsupplemented gel; $\square, \mathrm{NO}_{3}^{-}$, 3-nitrophenol-supplemented gel; $\square, \mathrm{NO}_{3}^{-}$, unsupplemented gel.

Fig. 4. Bacterial populations present in gel-stabilized model freshwater sediment ecosystems after 12 weeks incubation. (a) Unsupplemented; (b) 3-nitrophenol supplemented. O, SRB; O, denitrifying bacteria; $\boldsymbol{\square}$, bacteria dissimilating nitrate to ammonia; $\square$, ammonia-oxidizing bacteria; $\boldsymbol{\Delta}$, nitriteoxidizing bacteria. 


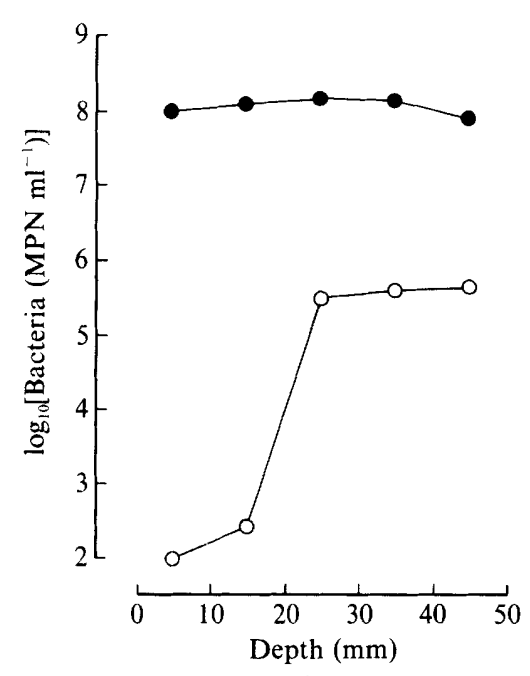

Fig. 5

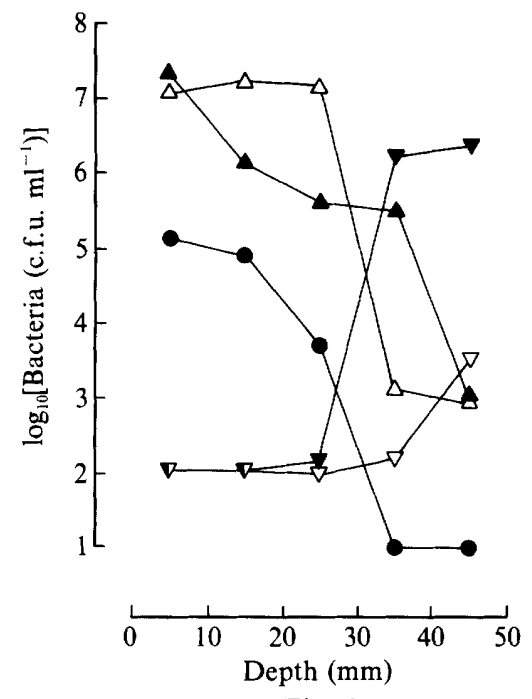

Fig. 6

Fig. 5. Populations of SRB present in gel-stabilized model marine sediment systems after 12 weeks incubation. $O$, Unsupplemented gels; $O$, hexadecane/naphthalene-supplemented gels.

Fig. 6. Populations of heterotrophic bacteria present in gel-stabilized model marine sediment ecosystems after 12 weeks incubation. Open symbols, unsupplemented gel; filled symbols, hexadecane/ naphthalene-supplemented gel. $\boldsymbol{O}$, Hexadecane utilizers; $\boldsymbol{\Delta}, \triangle$, total aerobic heterotrophs; $\boldsymbol{\nabla}, \nabla$, total anaerobic heterotrophs.

freshwater systems. Sulphate was found to be rapidly depleted, particularly in the deeper portions of the gels (Fig. 2). There were marked differences in the concentrations of nitrogenous ions in the supplemented and unsupplemented agar gel systems (Fig. 3). The 3-nitrophenolsupplemented gels contained very little $\mathrm{NH}_{4}^{+}$but there was a steep gradient of $\mathrm{NO}_{3}^{-}$downwards from the surface, whereas there was an increase in $\mathrm{NO}_{3}^{-}$down through the unsupplemented gel column. Nitrite was not detected in any gel.

\section{Bacterial populations}

In the agar gel systems similar populations of SRB, denitrifying bacteria and bacteria dissimilating nitrate to ammonia were observed in all gels (Fig. 4). Denitrifying bacteria were numerous at all depths but very few ammonia-oxidizing bacteria were detected. Nitriteoxidizing bacteria were most numerous in the upper portions of the gel columns and the highest numbers of SRB were present in the deeper sections of the gel.

The profiles of SRB in the unsupplemented silica-gel-stabilized model systems were similar to those observed in the agar gel systems, namely increasing population size with increasing depth, but supplementation with the hydrocarbon substrates produced a higher overall population that was evenly distributed throughout the gel column (Fig. 5). Aerobic hexadecane-utilizers were detected in the gels, with the population being highest in the upper regions of the gel column (Fig. 6). The profiles of aerobic and anaerobic heterotrophs exhibited maximum population sizes in the upper and lower regions of the gel column, respectively (Fig. 6).

\section{DISCUSSION}

The pollutants chosen for these investigations were employed for ease of assay, known biodegradability and because they are representative of groups of known environmental contaminants. Nitrophenols are important as pollutants in their own right and are produced during the microbial metabolism of some pesticides. Hexadecane and naphthalene were chosen 
as common representative aliphatic and aromatic petroleum hydrocarbons, respectively. The substrate concentration employed in the upper gel layer was designed to provide the equivalent of $20 \mu \mathrm{g} \mathrm{ml}^{-1}$ throughout the sloppy gel volume $(600 \mathrm{ml})$, assuming complete free diffusion. This concentration was chosen to provide a balance between minimizing toxic effects and enabling ready detection of effects and degradation. There was no significance in the choice of gelling agents for the different sediments and the methods were chosen as illustrative examples of gelstabilized systems.

The normal mode of entry of pollutants into the sediment column is from the surface, and this was modelled in these experiments. 3-Nitrophenol is water soluble, and it diffused rapidly through the sloppy agar gel column to produce an equilibrium concentration of approximately $20 \mu \mathrm{g} \mathrm{ml}^{-1}$. In inoculated gels there was a significant decrease in total 3-nitrophenol with time that was not observed in uninoculated gels, suggesting that biodegradation of 3-nitrophenol was occurring. Further evidence in support of biodegradation was provided by analyses of nitrogenous ions through the gel profiles (Fig. 3). The 3-nitrophenol-supplemented gel system contained a high concentration of nitrate in the upper layers of the column which was not present in the unsupplemented gels. Barik et al. (1976) observed the release of nitrite during the metabolism of 3-nitrophenol by a soil community. If nitrite was produced by the sediment community employed in this study, it may have been rapidly oxidized by the high numbers of nitrite-oxidizing bacteria present (Fig. 4). Hexadecane and naphthalene are hydrophobic molecules and it was expected that diffusion through the gel column would be limited. However, naphthalene proved undetectable during the incubation period, probably owing to rapid volatilization of this compound during the preparation of the gel system. In contrast, hexadecane was found to be distributed throughout the gel column despite its low solubility and the greater rigidity of the silica gel. The distribution of hydrocarbons through static zones of primarily aqueous material has prevously been noted by Moosavi \& Hamilton (1987) in marine sulphuretum systems supplemented with crude oil. Inoculated gel systems exhibited decreasing total hexadecane concentrations with time. This finding, together with the isolation of significant numbers of hydrocarbon-degrading bacteria from the gel systems (Fig. 6), would suggest that efficient biodegradation of this material was occurring in the aerobic upper portions of the gel column.

The effects of contaminants on some of the processes involved in the cycling of nitrogen and sulphur were investigated. 3-Nitrophenol had little impact on the total numbers and distribution of bacteria in the gel columns determined after 12 weeks incubation (Fig. 4). However, the addition of 3-nitrophenol resulted in more rapid depletion of sulphate in the gel column. This may have been due to increased activity of heterotrophic bacteria causing oxygen depletion or to these organisms producing assimilable organic carbon for the SRB.

Hexadecane supplementation had a major impact upon the SRB population in the gel systems (Fig. 5). The presence of hexadecane resulted in a large increase in population size and the bacteria were distributed throughout the depth profile, including the upper, potentially aerobic, zones. It is possible that the observed effect was due to the production by hexadecane-degrading heterotrophs of metabolites which served as growth substrates for the SRB or that the activity of heterotrophs resulted in oxygen depletion. It has been reported previously that sulphatereducing activity in sediments may be stimulated by hydrocarbon contamination (Floodgate, 1984). Supplementation with xenobiotics resulted in a decreased population of aerobic heterotrophs and an increased number of anaerobic heterotrophs (Fig. 6). These observations support the hypothesis that active biodegradation of the hydrocarbon substrate was causing oxygen depletion. Since molecular oxygen is required for significant rates of biodegradation of virtually all petroleum hydrocarbons (Atlas, 1981), such a lowering of oxygen concentration in the environment may result in decreased mineralization of hydrocarbons, and this would be further enhanced by a lowering of redox potential owing to the generation of sulphide itself due to the activity of SRB induced by oxygen depletion.

In this study we have attempted to survey a range of techniques in order to demonstrate that the use of gel-stabilized model sediment ecosystems has great potential in the study of the fate and effects of materials in sediments and, indeed, other stratified environments. The major 
advantage of gel-stabilized systems is that they render sediment microbial processes clearly visible and enable simple methods of sampling and analysis to be employed. Colloidal silica was found to be more difficult to prepare and handle than agar and there was significant shrinkage of the silica gel due to water loss during the incubation period, which may have altered the water activity of the environment. Whilst the use of a commercial colloidal silica suspension - for example, Ludox (Du Pont) or Bayer Silica Sol - may overcome some of the preparation problems, water loss is likely to remain a major difficulty (Temple, 1949; Bridson \& Brecker, 1970). Consequently, agar is likely to be the gelling agent chosen by most experimenters who wish to employ gel model systems. Provided it is understood that the movement of substrates and micro-organisms through gel systems may differ from the situation in natural sediments, particularly with respect to interactions with sediment surfaces, then gel-stabilized model systems provide a valuable experimental tool for the microbial ecologist. Indeed, MacFarlane $e t$ al. (1984) found that the profiles of $\mathrm{pH}, E_{\mathrm{h}}$ and dissolved oxygen in gel model systems were virtually identical to those measured in the estuarine sediment from which the inoculum was obtained. Gel-stabilized systems have also been employed to model other stratified environments, for example oil storage tanks (Wimpenny et al., 1981), to study the effects of physicochemical gradients on the growth of individual strains (Whittenbury, 1963; Wimpenny et al., 1981) and to investigate interactions within populations (e.g. oil degradation by defined microbial populations; Rees et al., 1987). Further developments are awaited with interest.

We would like to thank Dr J. W. T. Wimpenny, University of Wales College of Cardiff, and Dr R. A. Herbert, University of Dundee, for valuable advice and discussion on gel-stabilized systems.

\section{REFERENCES}

Aleem, M. I. H. \& Alexander, M. (1958). Cell-free nitrification by Nitrobacter. Journal of Bacteriology 76, $510-514$.

Alexander, M. \& Clarke, F. E. (1965). Nitrifying bacteria. In Methods of Soil Analysis, pp. 1477-1483. Edited by C. A. Black. Madison, Wisconsin: American Society of Agronomy.

Atlas, R. M. (1981). Microbial degradation of petroleum hydrocarbons: an environmental perspective. Microbiological Reviews 45, 180-209.

Barik, S., Siddaramappa, R. \& Sethunathan, N. (1976). Metabolism of nitrophenols by bacteria isolated from parathion-amended flooded soil. Antonie van Leeuwenhoek 42, 461-470.

BRIDSON, E. Y. \& BRECKER, A. (1970). Design and formulation of microbial culture media. Methods in Microbiology 3A, 229-303.

Clarke, K. R. \& Owens, N. J. B. (1983). A simple and versatile micro-computer program for the determination of 'most probable number'. Journal of Microbiological Methods 1, 133-137.

Floodgate, G. D. (1984). The tate of petroleum in marine ecosystems. In Petroleum Microbiology, pp. 355-397. Edited by R. M. Atlas. New York: Macmillan.

Jones, J. G., Simon, B. M. \& Horsley, R. W. (1982). Microbiological sources of ammonia in freshwater lake sediments. Journal of General Microbiology 128 , 2823-2831.

MacFarlane, G. T. \& Herbert, R. A. (1984). Dissimilatory nitrate reduction and nitrification in estuarine sediments. Journal of General Microbiology 130, 2301-2308.

MacFarlane, G. T., Russ, M. A., Keith, S. M. \& Herbert, R. A. (1984). Simulation of microbial processes in estuarine sediments using gel-stabilized systems. Journal of General Microbiology 130, 29272933.

Moosavi, A. N. \& Hamilton, W. A. (1987). Microbial corrosion studies in a marine sulphuretum. In Microbiological Problems in the Offshore Oil Industry, pp. 13-26. Edited by E. C. Hill, J. L. Shennan \& R. J. Watkinson. Chichester: Wiley.

Postgate, J. R. (1979). The Sulphate-reducing Bacteria. Cambridge: Cambridge University Press.

Raymond, D. G. M. \& Alexander, M. (1971). Microbial metabolism and cometabolism of nitrophenols. Pesticide Biochemistry and Physiology 1, $123-130$.

Rees, E. A., Tughan, C. S., Russ, M. A. \& Herbert, R. A. (1987). A study of the microbial decomposition of oil under anaerobic conditions using gel-stabilized model systems. In Microbiological Problems in the Offshore Oil Industry, p. 248. Edited by E. C. Hill, J. L. Shennan \& R. J. Watkinson. Chichester: Wiley.

Temple, K. L. (1949). A new method for the preparation of silica gel plates. Journal of Bacteriology 57, 383.

WhITTENBURY, R. (1963). The use of soft agar in the study of conditions affecting the utilization of fermentable substrates by lactic acid bacteria. Journal of General Microbiology 32, 375-384.

Wimpenny, J. W. T., CoOmbs, J. P., Lovitt, R. W. \& WhitTaKer, S. G. (1981). A gel-stabilized model ecosystem for investigating microbial growth in spatially ordered solute gradients. Journal of General Microbiology 127, 277-287. 